\title{
CULTURAS DE COBERTURA DO SOLO E ADUBAÇÃO NITROGENADA NO MILHO EM PLANTIO DIRETO ${ }^{1}$
}

\author{
Soil cover crops and nitrogen fertilizing in corn in no tillage planting
}

\author{
Regiani Aparecida Alexandre Ohland ${ }^{2}$, Luiz Carlos Ferreira de Souza ${ }^{3}$, Luís Carlos Hernani", \\ Marlene Estevão Marchetti ${ }^{3}$, Manoel Carlos Gonçalves ${ }^{3}$
}

\begin{abstract}
RESUMO
Com o objetivo de estudar a influência da cultura de cobertura do solo antecessora sobre os componentes de produção da cultura do milho, desenvolveu-se um experimento em um Latossolo Vermelho distroférrico no Núcleo Experimental de Ciências Agrárias - NCA, da Universidade Federal do Mato Grosso do Sul - UFMS, Campus de Dourados - MS. O delineamento experimental foi em blocos casualizados, com os tratamentos arranjados em esquema de parcelas subdivididas, com quatro repetições. As parcelas experimentais foram constituídas pelas culturas antecessoras (ervilhaca peluda e nabo forrageiro) e as subparcelas foram representadas por cinco doses de nitrogênio em cobertura (0, 50, 100, 150 e $200 \mathrm{~kg}$ de $\mathrm{N}^{-1}$ ) na cultura do milho, divididas em duas aplicações, nos estádios de quatro e de oito folhas. As culturas antecessoras apresentam efeitos diferenciados sobre os componentes de produção do milho cultivado subseqüentemente. A ervilhaca peluda é mais efetiva do que o nabo forrageiro quanto às características de: matéria seca da parte aérea, diâmetro da espiga, peso de mil grãos e teor de nitrogênio nos grãos de milho. Independente da cultura antecessora, a adição de nitrogênio eleva a produtividade de grãos de milho.
\end{abstract}

Termos para indexação: Zea mays, plantio direto, nabo forrageiro, ervilhaca peluda, doses de N.

\begin{abstract}
With the aim of studying the preceding soil cover crop influence upon the corn crop production components an experiment in a disttrophic Red Latossol was developed at the Núcleo de Ciências Agrárias - NCA, of the Universidade Federal de Mato Grosso do Sul - UFMS, Campus de Dourados - MS. The experimental design was randomized blocks, with the treatments arranged in a split plots pattern, with four replications. The experimental plots were constituted by the former crops (hairy vetch and forage turnip) and the split plots were represented by five surface nitrogen doses (0, 50, 100, 150, and 200 kg $\mathrm{N} / \mathrm{ha}^{-1}$ ) in the corn crop, divided into two applications, in the four and eight leaves growth stages. The preceding crops present differentiated effects on the corn cultivated afterwards production components. The hairy vetch is more effective than the forage turnip in relation to the following traits: above ground dry matter, ear diameter, one thousand grains weight, and corn grains nitrogen content. Despite the previous crop, nitrogen addition increases corn grains productivity.
\end{abstract}

Index terms: Zea mays, no tillage planting, forage turnip, hairy vetch, and $\mathrm{N}$ doses.

(Recebido para publicação em 23 de abril 2003 e aprovado em 17 de setembro de 2004)

\section{INTRODUÇÃO}

Devido à grande exigência de nitrogênio, o milho é uma cultura altamente responsiva a esse fertilizante, apresentando incrementos em várias características que influenciam a produção final. Têm-se sido mostrado em trabalhos que, em geral, 70 a $90 \%$ dos experimentos com milho executados em campo no Brasil responderam à aplicação de nitrogênio (CANTARELLA \& RAIJ, 1986; LANTMANN et al., 1986). A magnitude das respostas nas condições brasileiras tem sido variável, e na maioria das pesquisas verificam-se respostas significativas a doses entre 30 e $90 \mathrm{~kg} \mathrm{ha}^{-1}$, em parte devido aos níveis de produtividade relativamente baixos alcançados no campo. No entanto, são encontradas respostas para até $200 \mathrm{~kg} \mathrm{ha}^{-1}$ (GROVE et al., 1980; MELLO et al., 1988; RAIJ et al., 1981).

$\mathrm{O}$ cultivo de leguminosas antecedendo o milho aumenta a disponibilidade de $\mathrm{N}$ no solo, a absorção de $\mathrm{N}$ pela planta e o rendimento de grãos, sendo o sistema de manejo da leguminosa importante para a melhoria dos componentes de produção da cultura.

\footnotetext{
1. Extraído da dissertação de mestrado apresentada pela primeira autora à Universidade Federal de Mato Grosso do Sul/UFMS - Dourados, MS

2. Engenheira Agrônoma Depto. de Fitotecnia/UFMS - Br-463 - Km 12 - Dourados, MS - 79.825-070 regianiohland@bol.com.br

3. Engenheiro Agrônomo, Prof. Dr. Departamento de Ciências Agrárias/UFMS - Icfsouza@ceud.ufms.br

4. Engenheiro Agrônomo, Dr. CPAO - Embrapa - Caixa Postal 661 - 79.804-970 Dourados, MS - hernani@cpao.embrapa.br
} 
Ao se comparar diferentes sistemas de manejo da ervilhaca, constatou-se que essa leguminosa dessecada um dia antes da semeadura do milho proporcionou um aumento de $20 \%$ no rendimento de grãos da gramínea, quando comparado com a ervilhaca dessecada quinze dias antes da semeadura, o que mostra a alta taxa de mineralização do nitrogênio dessa leguminosa (ARGENTA et al., 1999). Por outro lado, espécies de gramíneas com alta relação $\mathrm{C} / \mathrm{N}$ apresentam baixa taxa de decomposição e oferecem maior proteção do solo durante todo o ciclo do milho. Dentre essas, a mais utilizada no sul do País é a aveia-preta, por apresentar rusticidade, rápido desenvolvimento inicial e alta produção de massa seca (SÁ, 1996).

A utilização da ervilhaca em consórcio com a aveia-preta não reduziu o rendimento de matéria seca para a cobertura de solo em relação ao cultivo isolado de aveia. Também foi observado que a introdução de ervilhaca em consórcio com aveia diminuiu a necessidade de adubação nitrogenada para o cultivo do milho em sucessão (BORTOLINI et al., 2000). A associação de sistemas conservacionistas de preparo do solo (reduzido e direto) e o uso de leguminosas proporcionaram melhor fornecimento de $\mathrm{N}$ ao milho (efeito imediato). Além disso, em subparcelas nas quais se utilizou rotação com aveia + ervilhaca/milho + caupi , houve incrementos de $26 \%$ e $19 \%$ na quantidade de $\mathrm{N}$ absorvido e rendimento de grãos da cultura, respectivamente, em relação ao tratamento com uso de apenas aveia/milho (AMADO et al., 1998).

O nabo forrageiro apresenta elevada capacidade de reciclagem de nutrientes, principalmente nitrogênio e fósforo, tornando-o uma importante espécie para fazer parte de esquemas de rotação de culturas. Essa leguminosa desenvolve-se em solos de fertilidade média, podendo promover uma cobertura de $70 \%$ do solo já aos 60 dias após o plantio. Suas raízes apresentam importantes efeitos físicos no solo, descompactando o e promovendo um preparo biológico. Além do seu emprego como cobertura do solo, o nabo forrageiro pode ser usado na alimentação de bovinos de leite e de corte, em pastejo direto ou cortado e distribuído em cochos. Pode ser consorciado com a aveia, centeio, ervilha forrageira, tanto para adubação verde como para forragem (CALEGARI, 1990).

Objetivo-se com este trabalho avaliar o efeito das culturas de ervilhaca peluda e de nabo forrageiro como antecessoras e de doses de nitrogênio em cobertura no milho, na produtividade dessa gramínea em sistema de plantio direto.

\section{MATERIAL E MÉTODOS}

Este trabalho foi realizado no Núcleo Experimental de Ciências Agrárias, da Universidade Federal de Mato Grosso do Sul, localizado no município de Dourados, a $22^{\circ} 14^{\prime}$ de latitude Sul e $54^{\circ}$ 49' de longitude Oeste e altitude de 452 metros, no ano agrícola de 2000/2001. O solo da área experimental é o Latossolo Vermelho distroférrico, originalmente sob vegetação de Savana Arbórea Aberta (campo cerrado). Este trabalho é parte de um experimento de longa duração, iniciado em outubro de 1997, envolvendo sistemas de produção de grãos baseados em rotação de culturas e plantio direto. A seqüência das culturascultivadas no verão e no inverno, de 1997 até 2000, nas parcelas com nabo forrageiro e nas com a ervilhaca peluda foram, respectivamente: arroz-naboalgodão-sorgo-algodão-nabo forrageiro-milho e: milhotrigo-soja-sorgo-soja-ervilhaca peluda-milho. Pelos resultados da análise química das amostras compostas do solo obtidas da camada 0-0,2 m, em março de 2000, verificaram-se: $\mathrm{pH}$ em $\mathrm{CaCl}_{2}=4,8$; matéria orgânica (MO)=28,9 $\mathrm{g} \mathrm{dm}^{-3} ; \mathrm{P}=10,2 \mathrm{mg} \mathrm{dm}{ }^{-3} ; \mathrm{K}=4, \mathrm{Ca}=37,8$; $\mathrm{Mg}=15,1$ e CTC $=120,4 \mathrm{mmol}_{\mathrm{C}} \mathrm{dm}^{-3}$.

O delineamento experimental foi em blocos casualizados, com os tratamentos (culturas de cobertura e dose de $\mathrm{N}$ em cobertura para o milho subsequente) arranjados em esquema de parcela subdividida, com quatro repetições. As parcelas foram constituídas pelas culturas de cobertura: ervilhaca peluda (Vicia villosa Roth) e nabo forrageiro ( Raphanus sativus var. oleiferus Metzg.), semeadas no outono de 2000, e as subparcelas, corresponderam a cinco doses de nitrogênio (0, 50, 100, 150 e 200 kg de $\mathrm{N} \mathrm{ha}^{-1}$ ) aplicado em cobertura na cultura do milho cultivado subseqüentemente, na primavera de 2000 (safra 2000/2001).

Cada parcela foi constituída por $11 \mathrm{~m}$ de largura por $36 \mathrm{~m}$ de comprimento, e para implantação das subparcelas foram cultivadas quatro linhas de milho, com sete metros de comprimento, espaçadas entre si de $0,90 \mathrm{~m}$.

A adubação de nitrogênio em cobertura foi realizada manualmente a lanço, sobre a superfície do solo, em duas épocas, sendo a metade da dose aplicada no estádio de quatro folhas, e a outra metade no estádio de oito folhas completamente desenvolvidas, utilizandose como fonte a uréia.

As culturas de nabo forrageiro e ervilhaca peluda, que antecederam ao milho no sistema de rotação de culturas, foram implantadas na segunda quinzena de 
abril, com semeadora para plantio direto na densidade de 30 sementes por metro linear e espaçamento de 0,17 $\mathrm{m}$ entre linhas, em ambos os casos. Essas culturas foram manejadas com rolo-faca no florescimento pleno, sendo a rebrota dessecada com o herbicida glyphosate, na dose de $0,75 \mathrm{~L} \mathrm{ha}^{-1}$. O milho foi semeado sobre os resíduos culturais dessas espécies, com semeadora de plantio direto utilizando-se o híbrido simples DKB 350, num espaçamento de 0,9 m entre linhas e população de 55 mil plantas ha $^{-1}$, na segunda quinzena de setembro de 2001 . A adubação de semeadura foi de $300 \mathrm{~kg} \mathrm{ha}^{-1}$, da fórmula 7-20-20.

O controle de plantas daninhas foi em pósemergência, utilizando-se o herbicida nicossulfuron, na dose de 1,2 $\mathrm{L} \mathrm{ha}^{-1}$. A Spodoptera frugiperda foi controlada com o inseticida fisiológico diflubenzuron, na dose de $100 \mathrm{~g} \mathrm{ha}^{-1}$.

Foi avaliada na cultura do milho a produção da matéria seca da parte aérea, realizada no florescimento masculino, coletando-se cinco plantas ao acaso dentro das subparcelas, por tratamento e repetição. As plantas foram cortadas rente ao solo, sendo imediatamente trituradas, pesando-se a matéria fresca; em seguida, foi determinada a matéria seca, utilizando-se estufa com circulação forçada de ar na temperatura de $70{ }^{\circ} \mathrm{C}$, até peso constante. Também foram avaliados o diâmetro e o comprimento de espigas, o peso de mil grãos, a produtividade e o teor de nitrogênio nos grãos.

Para avaliar a produção de grãos, tomaram-se as duas linhas centrais de cada subparcela, descartando-se na extremidade das linhas um metro como bordadura e definindo a área útil de 5 x 0,9 m. A produtividade foi determinada após a debulha das espigas colhidas, corrigindo-se o grau de umidade para $13 \%$, sendo os valores expressos em $\mathrm{kg} \mathrm{ha}^{-1}$. O teor de nitrogênio no tecido vegetal da cultura do milho foi determinado pelo método semi-micro Kjeldahl (MALAVOLTA et al., 1997).

Na análise de variância dos dados, o efeito das culturas antecessoras foi avaliado pelo teste $\mathrm{F}$ a $5 \%$ de probabilidade e o das doses de nitrogênio pelo de contrastes ortgonais, comparando o tratamento zero de nitrogênio $\left(\mathrm{M}_{0}\right)$ com os tratamentos com aplicação de $\mathrm{N}$ em cobertura: $50 \mathrm{~kg}$ de $\mathrm{N}$ ha ${ }^{1}\left(\mathrm{M}_{50}\right) ; 100 \mathrm{~kg}$ de $\mathrm{N} \mathrm{ha}^{-1}\left(\mathrm{M}_{100} ;\right) ; 150 \mathrm{~kg}$ de $\mathrm{N}$ ha ${ }^{-1}\left(\mathrm{M}_{150}\right)$; e $2000 \mathrm{~kg}$ de $\mathrm{N}$ ha ${ }^{-1}\left(\mathrm{M}_{200}\right)$, considerando a média das culturas antecessoras, que foram testados pelo teste de Dunnett a 5\% de probabilidade.

\section{RESULTADOS E DISCUSSÃO}

O milho semeado após a ervilhaca peluda apresentou na média maior acúmulo de matéria seca na parte aérea, diferindo significamente $(\mathrm{P}<0,05)$ dos valores obtidos quando semeado em sucessão ao nabo forrageiro (Tabela 1).

A comparação de médias de produção de matéria seca da parte aérea dos tratamentos com adição de $\mathrm{N}$, em relação ao tratamento com dose zero de $\mathrm{N}$, foi significativa apenas para o tratamento com adição de $150 \mathrm{~kg} \mathrm{ha}^{-1}$, o qual gerou um incremento de 27,5 \% (Tabela 2).

Segundo Fancelli (1988), a produção de massa seca é influenciada pelo genótipo e pelas condições ambientais, sendo importante principalmente porque os fotoassimilados armazenados no colmo da planta poderão translocar para os grãos durante a fase de enchimento deles.

Marriel et al. (2000), analisando a produtividade de grãos em populações de milho cultivadas sob estresse de nitrogênio, concluíram que o acúmulo de massa seca da parte aérea poderia ser usado como indicador para a identificação preliminar de populações de milho eficientes no uso de nitrogênio. Também encontraram correlação significativa para massa seca da parte aérea no florescimento e a produção de grãos. Em pesquisa conduzida por Cereta et al. (1994), esses obtiveram maior peso de massa seca $(6,1$ toneladas.ha${ }^{1}$ ), utilizando-se o híbrido Cargill-484-A, semeado após o feijão de porco.

Não houve diferença significativa para comprimento de espigas, em função da cultura antecessora, doses de nitrogênio e para a interação. Para o diâmetro de espigas houve diferença significativa $(\mathrm{p}<0,05)$ entre as culturas antecessoras. Independente da dose de $\mathrm{N}$ aplicado, verificou-se que o milho semeado após a ervilhaca peluda proporcionou incrementos no diâmetro da espiga, diferindo significativamente da sucessão nabo forrageiro/milho (Tabela 1).

O comprimento e o diâmetro de espiga, o número de espigas por área e a densidade dos grãos são características que determinam o potencial de produtividade. $\mathrm{O}$ diâmetro de espiga está estreitamente relacionado com enchimento de grãos e número de fileiras de grãos por espiga, que também é influenciado pelo genótipo.

O milho semeado após a ervilhaca peluda apresentou maior peso médio de mil grãos em relação ao semeado após o nabo forrageiro, independente das doses de nitrogênio (Tabela 1 ). O peso da massa de grãos é uma característica influenciada pelo genótipo, pela disponibilidade de nutrientes e pelas condições climáticas durante os estádios de enchimento dos grãos. 
TABELA 1 - Valores médios de matéria seca da parte aérea da planta, diâmetro e comprimento de espiga, peso de 1000 grãos, produtividade de grãos e teor de nitrogênio nos grãos, em função da cultura antecessora. Dourados-MS, 2002.

\begin{tabular}{|c|c|c|c|}
\hline \multirow{2}{*}{ Variáveis } & \multirow{2}{*}{$\begin{array}{c}\text { CV (a) } \\
(\%)\end{array}$} & \multicolumn{2}{|c|}{ Cultua antecessora } \\
\hline & & Ervilhaca Peluda & Nabo Forrageiro \\
\hline Matéria seca da parte aérea $\left(\right.$ g planta $\left.^{-1}\right)$ & 31,3 & $141,8 \mathrm{a}$ & $127,9 \mathrm{~b}$ \\
\hline Comprimento de espiga (cm) & 7,87 & $19,7 \mathrm{a}$ & $19,5 a$ \\
\hline Diâmetro de espiga (mm) & 3,54 & $50,2 \mathrm{a}$ & $48,8 b$ \\
\hline Peso de 1000 grãos (g) & 10,17 & $353,0 \mathrm{a}$ & $332,9 b$ \\
\hline Produtividade de grãos $\left(\mathrm{kg} \mathrm{ha}^{-1}\right)$ & 23,40 & $9809 a$ & $9447 a$ \\
\hline Teores de N nos grãos (\%) & 4,07 & $1,59 a$ & $1,49 b$ \\
\hline
\end{tabular}

${ }^{1}$ Médias seguidas pela mesma letra na linha não diferem entre si, pelo teste F, a 5\% de probabilidade.

TABELA 2 - Contraste dos valores médios de matéria seca da parte aérea do milho do tratamento com adição de nitrogênio, em relação ao tratamento com zero de N em cobertura. Dourados, 2002.

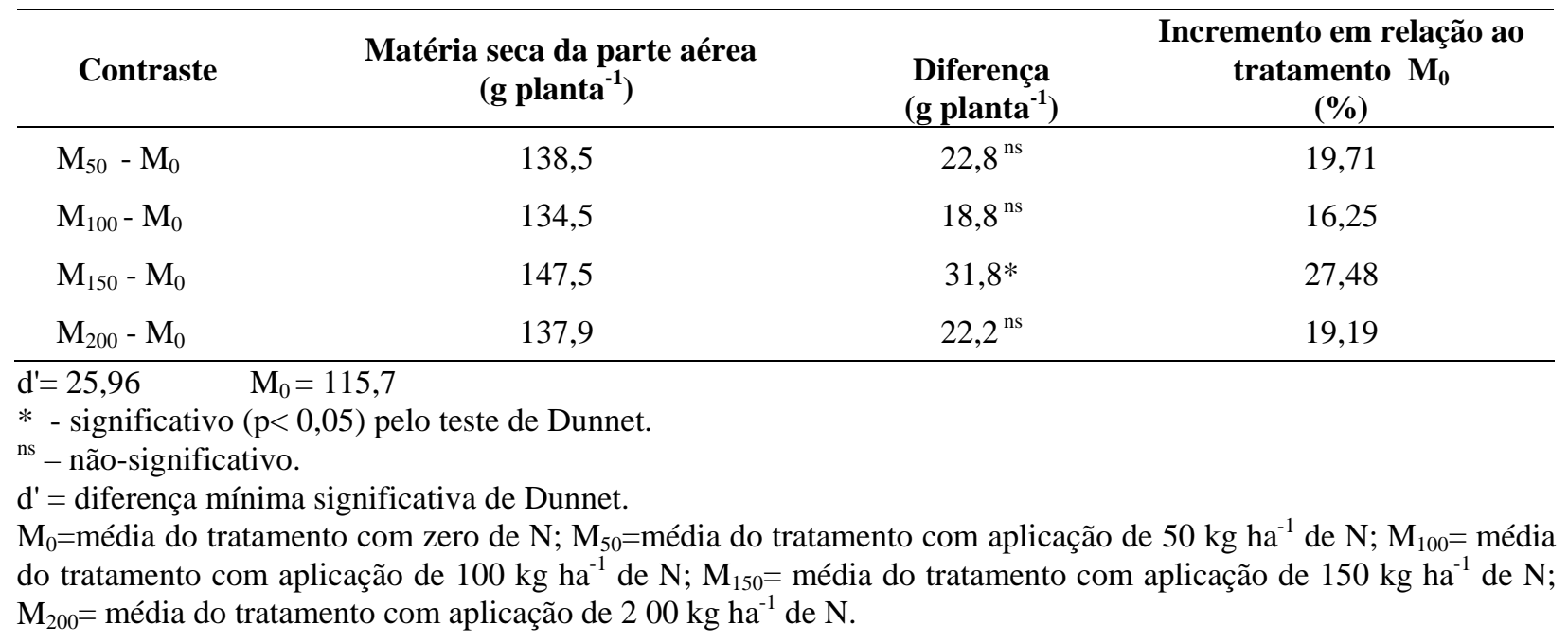

As temperaturas máximas e mínimas registradas durante o ciclo da cultura do milho foram adequadas para o bom desenvolvimento da planta, considerando-se que temperaturas médias noturnas inferiores a $24{ }^{\circ} \mathrm{C}$ diminuem a respiração celular, e quando ocorrem durante a fase de enchimento de grãos, contribuem para o maior acúmulo e translocação de fotoassimilados e, conseqüentemente, possibilitam maior deposição de matéria seca nos grãos (DOURADO NETO \& FANCELLI, 2000). Nesse sentido, os efeitos proporcionados pela ervilhaca peluda em relação ao nabo forrageiro aqui verificados estariam relacionados muito mais à sua capacidade em disponibilizar maiores conteúdos de $\mathrm{N}$ ao milho do que às condições climáticas durante 0 desenvolvimento dessa gramínea.

Os valores do peso de mil grãos obtidos nesta pesquisa, independente das culturas antecessora e doses de nitrogênio, foram superiores aos encontrados por Argenta et al. (1999), que variaram entre 286 e 314 g.mil grãos, semeados após a ervilhaca peluda dessecada 
um dia antes da semeadura do plantio, utilizando-se doses de uréia em cobertura de 0 e $100 \mathrm{~kg} \mathrm{ha}^{-1}$, respectivamente.

Comparando-se os contrastes dos valores médios de peso de mil grãos obtidos com as diferentes doses de $\mathrm{N}$, em relação ao tratamento com dose zero de $\mathrm{N}$, veriaram-se diferenças significativas para as doses de 150 e $200 \mathrm{~kg} \mathrm{ha}^{-1}$ com aumentos de 8,1 e 9,3\%, respectivamente (Tabela 3 ).

Para a produtividade de grãos, os resultados foram significativos $(\mathrm{p}<0,05)$ para doses de nitrogênio, não sendo significativos para cultura antecessora e para a interação. Apesar de não haver diferenças significativas para interação, independente da cultura anterior e de doses de nitrogênio, o milho cultivado após a evilhaca peluda produziu, em média, $9.809 \mathrm{~kg}$ ha $^{-1}$ e, após, o nabo forrageiro, $9.447 \mathrm{~kg} \mathrm{ha}^{-1}$ (Tabela 1), valor esse relativo a mais que o dobro da média obtida no ano agrícola 2000/2001 no Estado do Mato Grosso do Sul.

Deve-se ressaltar que o milho semeado após a ervilhaca peluda apresentou em magnitude, na dose zero de nitrogênio, maior peso de mil grãos (343,6 g) e maior produtividade (9219 $\mathrm{kg} \mathrm{ha}^{-1}$ ) em relação aos obtidos após o nabo forrageiro. Essa diferença pode estar relacionada a uma tendência de disponibilização de maior conteúdo de $\mathrm{N}$ para o milho proporcionada pela ervilhaca, comparada ao nabo forrageiro. Silva (2003) obteve na safra 2001/2002, na mesma área experimental, produtividade semelhante na sucessão ervilhaca peluda/milho e nabo forrageiro/milho, na ausência de adubação nitrogenada em cobertura, diferindo da sucessão aveia preta/milho, que produziu $5253 \mathrm{~kg} \mathrm{ha}^{-1}$.

A produtividade obtida pode ser atribuída à eficiência das culturas utilizadas como antecessoras, das condições climáticas favoráveis (temperatura e precipitação pluviométrica), da disponibilidade de nutrientes, e do potencial genético do híbrido utilizado. Durante a condução do experimento, foi registrada uma boa distribuição de chuva, com uma precipitação pluviométrica acumulada de $570 \mathrm{~mm}$, que contribuiu para o bom desenvolvimento da cultura e aproveitamento do $\mathrm{N}$ adicionado ao solo.

Em pesquisa desenvolvida no Estado do Paraná, utilizando o híbrido AG-513, também se obteve maior produtividade de grãos para o milho cultivado após a ervilhaca peluda (6.883 $\mathrm{kg} \mathrm{ha}^{-1}$ ), em relação ao semeado após o nabo forrageiro (5.755 $\left.\mathrm{kg} \mathrm{ha}^{-1}\right)$; em ambas as sucessões, a produtividade de grãos não diferiu entre a aplicação de 0 e $90 \mathrm{~kg} \mathrm{ha}^{-1}$ de nitrogênio (CALEGARI, 1990).

A comparação entre médias de produtividade de grãos de milho dos tratamentos com adição de $\mathrm{N}$, em relação ao tratamento com zero de $\mathrm{N}$, foi significativa para todas as doses de N. A adição de $200 \mathrm{~kg} \mathrm{ha}^{-1}$ de $\mathrm{N}$ em cobertura promoveu o maior acréscimo de produtividade na cultura do milho, independente das culturas de cobertura antecessoras (Tabela 4).

TABELA 3 - Contraste dos valores médios peso de mil grãos dos tratamento com adição de nitrogênio, em relação ao tratamento com zero de N em cobertura. Dourados, 2002.

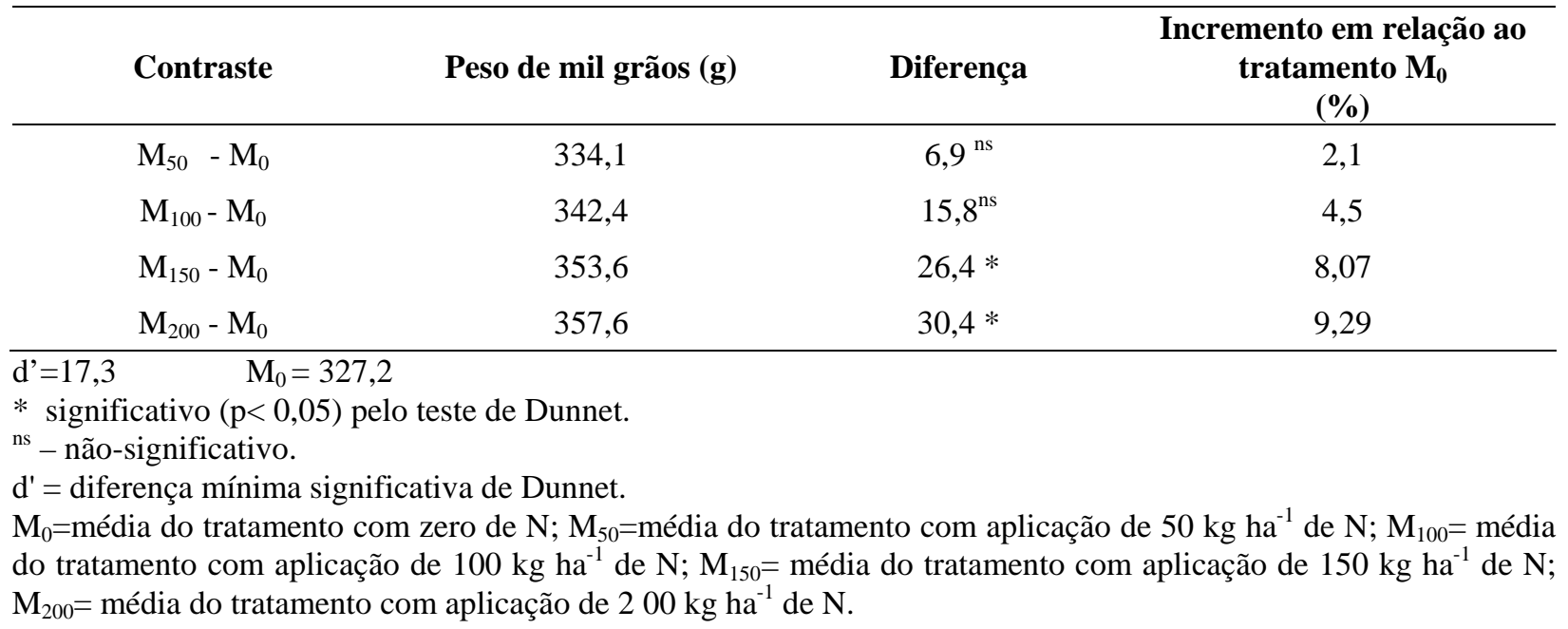

Ciênc. agrotec., Lavras, v. 29, n. 3, p. 538-544, maio/jun., 2005 
TABELA 4 - Contraste entre os valores médios de produtividade de grãos de milho dos tratamentos com adição de nitrogênio, em relação ao tratamento com zero de N em cobertura. Dourados-MS, 2002.

\begin{tabular}{|c|c|c|c|}
\hline Contraste & $\begin{array}{l}\text { Produtividade } \\
\left(\mathrm{kg} \mathrm{ha}^{-1}\right)\end{array}$ & $\begin{array}{l}\text { Diferença } \\
\left(\mathrm{kg} \mathrm{ha}^{-1}\right)\end{array}$ & $\begin{array}{c}\text { Incremento em relação ao } \\
\text { tratamento } M_{0} \\
(\%)\end{array}$ \\
\hline $\mathrm{M}_{50}-\mathrm{M}_{0}$ & 9.748 & $1.155^{*}$ & 13,4 \\
\hline $\mathrm{M}_{100}-\mathrm{M}_{0}$ & 9.777 & $1.184^{*}$ & 13,8 \\
\hline $\mathrm{M}_{150}-\mathrm{M}_{0}$ & 9.903 & $1.310^{*}$ & 15,2 \\
\hline $\mathrm{M}_{200}-\mathrm{M}_{0}$ & 10.117 & $1.524^{*}$ & 17,8 \\
\hline \multicolumn{4}{|c|}{$\begin{array}{l}\mathrm{M}_{0}=8.593 \\
\text { pelo teste de Dunnet. } \\
\text { hificativa de Dunnet. } \\
\text { com zero de } \mathrm{N} ; \mathrm{M}_{50}=\text { média do tratamento com aplicação de } 50 \mathrm{~kg} \mathrm{ha}^{-1} \text { de } \mathrm{N} ; \mathrm{M}_{100}=\text { média } \\
\text { ção de } 100 \mathrm{~kg} \mathrm{ha}^{-1} \text { de } \mathrm{N} ; \mathrm{M}_{150}=\text { média do tratamento com aplicação de } 150 \mathrm{~kg} \mathrm{ha}^{-1} \text { de N; } \\
\text { o com aplicação de } 200 \mathrm{~kg} \mathrm{ha}^{-1} \text { de } \mathrm{N} \text {. }\end{array}$} \\
\hline
\end{tabular}

Para o teor de nitrogênio nos grãos, os resultados da análise de variância foram significativos $(\mathrm{p}<0,05)$ para culturas de cobertura antecessoras, não tendo significância para doses de nitrogênio e para interação entre culturas e doses de nitrogênio. Independente das doses de nitrogênio, o milho cultivado após a ervilhaca peluda apresentou maiores teores de nitrogênio nos grãos (Tabela 1).

O pesquisador conduzida por Silva (2003) obteve menor acúmulo de nitrogênio nos grãos de milho(13,7 $\left.\mathrm{mg} \mathrm{g}^{-1}\right)$, quando semeado após a aveiapreta, diferindo significativamente dos valores obtidos na sucessão com ervilhaca peluda $\left(15,2 \mathrm{mg} \mathrm{g}^{-1}\right)$ e nabo forrageiro (15,6 mg g $\left.\mathrm{g}^{-1}\right)$, cujos valores foram semelhantes aos obtidos neste trabalho (Tabela 1)..

$O$ teor de nitrogênio nos grãos é muito importante, pois reflete a quantidade de proteína. Fernandes et al. (1999) relatam que $70 \%$ do nitrogênio da planta está contido nos grãos e, assim, é exportado.

\section{CONCLUSÕES}

As culturas de cobertura apresentam efeitos diferenciados sobre os atributos da cultura de milho cultivado subseqüentemente.

A ervilhaca peluda é mais efetiva do que o nabo forrageiro quanto às características de: matéria seca da parte aérea, diâmetro da espiga, peso de mil grãos e teor de nitrogênio nos grãos do milho.

Independente da cultura de cobertura, a adição de nitrogênio eleva a produtividade de grãos de milho.

\section{REFERÊNCIAS BIBLIOGRÁFICAS}

AMADO, T. J.; MIELNICZUK, J.; FERNANDES, S. B. V.; BAYER, C. Culturas de cobertura, acúmulo de nitrogênio total no solo e produtividade de milho. UFRG - Faculdade de Agronomia - Porto Alegre-RS. Revista Brasileira de Ciência do Solo, Campinas, v. 23, n. 3, p. 679-686, jul./set. 1998.

ARGENTA, G.; SILVA, P. R. F. da; BORTOLINI, C. G.; STRIEDER, M. L.; FORSTHOFER, E. L. Efeito de sistemas de manejo da ervilhaca comum sobre a cultura do milho semeada em sucessão. In: CONGRESSO NACIONAL DE MILHO E SORGO, 22., 1999, Uberlândia. Anais... Uberlândia: [s.n.], 1999.

BORTOLINI, C. G.; SILVA, P. R. F.; ARGENTA, G. Sistemas consorciados de aveia preta e ervilhaca comum como cobertura de solo e seus efeitos na cultura do milho em sucessão. Revista Brasileira de Ciência do Solo, Campinas, v. 24, p. 897-903, out./dez. 2000.

CALEGARI, A. Plantas para adubação verde de inverno no sudoeste do Paraná. Londrina: IAPAR, 1990. 37 p. (Boletim técnico, 35).

CANTARELLA, H.; RAIJ, B. van. Adubação nitrogenada no Estado de São Paulo. In: SANTANA, M. B. M. (Coord.). Adubação nitrogenada no Brasil. Ilhéus: CEPLAC/SBCS, 1986. p. 47-49. 
CERETA, C. A.; AITA, C.; BRAIDA, J. A.; PAVINATO, A.; SALET, T. L. Fornecimento de nitrogênio por leguminosas na primavera para o milho em sucessão nos sistemas de cultivo mínimo e convencional. Revista Brasileira de Ciências de Solo, Viçosa, v. 18, p. 215-220, 1994.

DOURADO NETO, D.; FANCELLI, A. L. Produção de milho. Guaíba: Agropecuária, 2000. 360 p.

FANCELLI, A. L. Influência do desfolhamento no desempenho de plantas e de sementes de milho (Zea mays L.). 1988. 172 f. Tese (Doutorado) - Escola Superior de Agricultura Luiz de Queiroz, Universidade de São Paulo, Piracicaba, 1988.

FERNANDES, L. A. C.; VASCONCELOS, C. A.; FURTINI NETO, A. E.; ROSCOE, R.; GUEDES, G. A. Preparo do solo e adubação nitrogenada na produção de grãos e matéria seca e acúmulo de nutrientes pelo milho. Pesquisa Agropecuária Brasileira, Brasília, v. 34, n. 9, p. 1691-1698, 1999.

GROVE, T. L.; RITCHE, K. D.; MADERMAN JÚNIOR, C. Nitrogen fertilization of maize on na Oxisol of the cerrado do Brazil. Agronomy Journal, Madison, v. 72, p. 261-265, 1980.

LANTMANN, A. F.; OLIVEIRA, E. L.; CHAVES, J. C. D.; PAVAN, A. Adubação no Estado do Paraná. In: SANTANA, M. B. M. (Coord.). Adubação nitrogenada no Brasil. Ilhéus: CEPLAC/SBCS, 1986. p. 19-46.

MALAVOLTA, E.; VITTI, G. C.; OLIVEIRA, S. A. Avaliação do estado nutricional das plantas. 2. ed.
Piracicaba: Associação Brasileira para Pesquisa da Potassa e do Fosfato, 1997. 319 p.

MARRIEL, I. E.; FRANÇA, G. E. de; VASCONCELOS, C. A.; GAMA, E. E. G. E.; SANTOS, M. X. dos; OLIVEIRA, A. C. Eficiência de absorção de nitrogênio e produtividade de grãos em populações de milho cultivadas sobre estresse. In: CONGRESSO NACIONAL DE MILHO E SORGO, 23., 2000, Uberlândia. Resumos... Sete Lagoas: ABMS/EMBRAPA Milho e Sorgo/UFU, 2000. p. 37.

MELLO, F. A. F.; ARZOLA, S.; KICHL, J. C.; BRITO NETO, J. Efeito das doses e modos de aplicação de uréia na produção de milho. Revista Brasileira de Ciência do Solo, Campinas, v. 12, p. 269-274, 1988

RAIJ, B. V.; FEITOSA, C. T.; CANTARELLA, H.; CAMARGO, A. P.; DECHEN, A. R.; ALVES, S.; SORDI, G.; VEIGA, A. A.; CAMPANA, M. P.; PETINELLI, A.; NERY, C. A análise de solo para discriminar resposta à adubação para a cultura do milho. Bragantia, Campinas, v. 40, p. 57-15, 1981.

SÁ, J. C. M. Manejo do nitrogênio na cultura do milho no sistema de plantio direto. 1996. $24 \mathrm{f}$. Dissertação (Mestrado) - Universidade Federal de Mato Grosso do Sul, Passo Fundo, 1996.

SILVA, D. A. Culturas antecessoras e adubação nitrogenada em um sistema de plantio direto sobre a cultura do milho. 2003. 49 f. Tese (Doutorado) Universidade Federal do Mato Grosso do Sul, Dourados, 2003. 